prof. dr hab. inż. Omelian Plachtyna

dr inż.Roman Żarnowski

mgr inz. Zbigniew Ktosowski

Uniwersytet Technologiczno-Przyrodniczy

w Bydgoszczy

\title{
Uklady napędowe z silnikiem indukcyjnym oraz falownikiem, sterowanym bez PWM, zasilane z sieci trakcyjnej
}

\begin{abstract}
$W$ artykule przedstawiono przeglad układów napędowych możliwych do zastosowania $w$ trakcji elektrycznej. Porównano cechy silnika trakcyjnego wielouzwojeniowego $z$ silnikami zasilanymi konwencjonalnie, omówiono moment elektromagnetyczny w stanie ustalonym kilku układów napędowych.
\end{abstract}

\section{Wprowadzenie}

Impulsem do elektryfikacji trakcji długodystansowej o wysokim napięciu znamionowym, stały się napędy o dopuszczalnie małych w takich okolicznościach stratach w liniach. Maszyna asynchroniczna, a w szczególności niezawodny silnik indukcyjny był kiedyś, i jest dziś „koniem pociagowym” trakcji. Jednakże, początkowo niewyszukane systemy trójfazowe oferowały skromną liczbę oszczędnych ekonomicznie prędkości i wkrótce zostały zdeklasowane przez napędy oparte na silniku komutatorowym. Ostatecznie, za wyjątkiem kilku przypadków, trakcja oparta na silnikach trójfazowych przy zasilaniu z sieci AC lub DC powróciła w latach siedemdziesiątych otrzymując niejako „drugie życie”. Sukces ekonomiczny transportu opartego o nową technologię napędów trójfazowych rósł, przekroczył granice państw i aż 17 różnych bezpiecznych systemów kolejowych jest używanych obecnie w całej Europie [6]. Toteż temu zagadnieniu poświęca się ciaggle wiele uwagi.

W chwili obecnej opracowano wiele elektrycznych układów napędowych z silnikami indukcyjnymi. Można tu wyróżnić dwa kierunki:

- układy z falownikami sterowanymi z użyciem PWM lub sterowaniem wektorowym,

- układy z zastosowaniem falowników wielopoziomowych (kaskadowych).

W układach z PWM występuje pewna znaczna zawartość wyższych harmonicznych, które oddziałują na silnik indukcyjny, zmuszając projektantów układów do tzw. „deratingu”. Przy czym wpływ tych harmonicznych na moment elektromagnetyczny jest stosunkowo mały.

Jednakże w bieżącym czasie badania nad topologią falowników przynoszą rozwiązania, które pozwalają na łączenie falowników wielopoziomowych w układy kaskadowe. Poprawna praca takiego falownika może odbywać się pod warunkiem zasilania ze źródeł izolowanych [5]. Dlatego alternatywą dla falownika 3-poziomowego PWM [1], który charakteryzuje się niskim czasem MTBF (mean time between failures)

byłoby zastosowanie falownika kaskadowego bez PWM. Toteż interesujący jest ten drugi kierunek, polegający na zastosowaniu falowników kaskadowych do napędów, do których autorzy mogą zaliczyć rozwiązania własne przedstawione dalej.

\section{Aspekt energetyczny systemu zasilania}

Przy zasilaniu siników trakcyjnych, z tych samych powodów co pierwotnie, to jest minimalizacji strat, stosuje się różne strategie. Aby zrozumieć strategie zasilania silników AC stosowane przez poszczególne firmy należy krótko przeanalizować pracę łączników półprze-wodnikowych zainstalowanych w urządzeniach (falownikach) stosowanych w trakcji elektrycznej.

Wiadomo, że łączniki w nich stosowane, nie mają idealnych charakterystyk, dlatego rozpraszają część energii, którą przewodzą. Jeśli rozpraszają jej zbyt wiele, mogą same ulec uszkodzeniu, lub doprowadzić do uszkodzenia innych elementów układu. Dlatego projektując układ należy rozważyć jak te straty zminimalizować.

Podczas przejścia ze stanu nieprzewodzenia do stanu przewodzenia obserwuje się pewien czas opóźnienia włączenia łącznika $t_{\mathrm{d}(\mathrm{on})}$ [2] po którym następuje czas narastania $t_{\mathrm{ri}}$. Tylko wtedy, gdy cały prąd $I_{\mathrm{o}}$ łącznika płynie przez łącznik dioda wsteczna jest przeciwnie spolaryzowana, a napięcie na łączniku spada do małej ustalonej wartości $U_{\text {on }} \mathrm{W}$ czasie $t_{\mathrm{fv}}$. Występują znaczne wartości chwilowe tych wielkości w czasie przełączania $t_{\mathrm{c}(\mathrm{on})}$.

$$
t_{\mathrm{c}(\mathrm{on})}=t_{\mathrm{ri}}+t_{\mathrm{fv}}
$$

Nawet uproszczona analiza przebiegu strat mocy chwilowej dowodzi, że rozpraszanie mocy chwilowej odbywa się głównie podczas włączania i wyłączania łączników. Te straty mocy można opisać przybliżoną równością (2)

$$
P_{\mathrm{s}}=0,5 U_{\mathrm{d}} I_{0} f_{\mathrm{s}}\left(t_{\mathrm{c}(\mathrm{on})}+t_{\mathrm{c}(\text { off })}\right)
$$


Jest to ważny wynik, ponieważ pokazuje, że straty w łącznikach półprzewodnikowych zmieniają się liniowo $\mathrm{w}$ zależności od częstotliwości przełączeń i czasów przełączania. Oznacza to, że jeśli dostępny jest łącznik o krótkich czasach przełączania, to możliwa jest praca przy wyższej częstotliwości, pożądanej ze względu na mniejsze filtry napięcia wyjściowego układu, jak i brak nadmiernych strat w nim. Innymi znacznymi stratami w łącznikach są straty powstałe w stanie przewodzenia

$$
P_{\mathrm{on}}=U_{\mathrm{on}} I_{0} f_{\mathrm{s}} t_{\mathrm{on}}
$$

Na podstawie powyższych rozważań można wnioskować, że napięcie przełączania i częstotliwość powinny być tak małe jak to jest technicznie uzasadnione. Są jeszcze inne liczne warunki, których ze względu na charakter tego artykułu nie rozważa się.

W trakcji o napięciu $3 \mathrm{kV}$ DC silniki AC są zasilane $\mathrm{z}$ falowników sterowanych z użyciem PWM przy częstotliwości $f_{\mathrm{PWM}}=300 \mathrm{~Hz}$ celem ograniczenia strat w falowniku $[2,5]$. Jednakże występujące wtedy straty w stosunku do znanych różnego typu, są dodatkowo większe do $80 \%$.

W trakcji o napięciu 15 lub $25 \mathrm{kV}$ AC (Niemcy) stosuje się $f_{\mathrm{PWM}} \leq 2000 \mathrm{~Hz}$, przy napięciu członu pośredniczącego $U_{\text {DCLink }} \leq 1000 \mathrm{~V}$, a straty dodatkowe wskutek występowania wyższych harmonicznych napięcia i prądu $\mathrm{w}$ maszynie $\mathrm{w}$ tym przypadku dochodzą do $20 \%$ mocy znamionowej silnika. Przykładowo, według informacji producenta, $w$ stosowanych przez ABB falownikach częstotliwość $f_{\text {PWM }}$ wynosi $1700 \mathrm{~Hz}$, a wykorzystując low voltage principle stosuje się układ obniżający napięcie tak, że $U_{\text {DCLink }}=400 \mathrm{~V}$. Straty dodatkowe są wtedy bardzo małe i nie przekraczaja $10 \%$ mocy znamionowej silnika. Straty w sieciach przesyłowych osiagają wartość do $10 \%$ mocy znamionowej silnika. Co gorsze, nie wszystkie te straty można wyznaczyć analitycznie, chociaż można je wyznaczać na drodze modelowania matematycznego układów.

Powyżej napisane prowadzi do wniosku, że ograniczanie strat dodatkowych zmusza nas do stosowania wyższej częstotliwości $f_{\mathrm{PWM}}$, albo zmniejszenia napięcia $U_{\text {DCLink }}$ poniżej $1000 \mathrm{~V}$.

Wysoka wartość stromości napięcia $\mathrm{d} u / \mathrm{d} t \mathrm{w}$ układach z PWM powoduje nierównomierny rozkład napięcia wewnątrz uzwojeń, wytwarzając szczególnie duży spadek napięcia na pierwszych kilku zwojach. Przepięcia te uszkadzają izolację międzyzwojowa, obliczaną tradycyjnie na $20 \mathrm{~V}$ (jedna warstwa emalii) [8]. Fakt ten, jak i inne opisane dalej moga przyczyniać się do atrakcyjności układów kaskadowych falowników (bez PWM).

Rys. 2. Sposób kształtowania napięcia na silniku (z rys. 1), przy czym $u_{\mathrm{d}}$ stanowi przyłożone do układu napięcie stałe, -a) aspekt teoretyczny, -b) napięcie badane [7]

\section{Analiza poszczególnych ukladów (bez PWM)}

Dalej analizuje się silnik indukcyjny z kaskadowym falownikiem napięcia mogący pracować w sieci DC (rys. 1). Ten przypadek wymaga zastosowania liniowego przekształtnika impulsowego (choppera), który jednak w sposób zasadniczy obniża sprawność napędu jako całości $[3,7]$. Napięcie z układu ma wysoką jakość parametrów poprzez to, że wyeliminowano z niego najbardziej znaczące harmoniczne.

Na rysunku 1 i następnych celowo, dla przejrzystości, pominięto informacje o układach sterowania. Faktycznie we wszystkich tych układach występują przekształtniki impulsowe na wejściu lub zamiennie prostowniki sterowane. Napięcie silnika i częstotliwość falowników są regulowane zgodnie z zasadą $U / f=$ const.

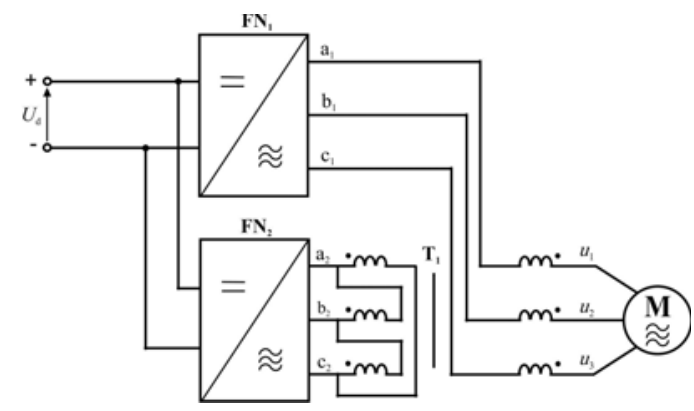

Rys. 1. Układ falownika kaskadowego zasilającego silnik
indukcyjny, korzystny dla silnika

Falownik 2VI (rys. 1) zasila napięciem wyjściowym spóźnionym w stosunku do falownika 1VI o $30^{\circ}$ transformator, który także wnosi opóźnienie o $30^{\circ}$.

Przekształtnikowe układy napędowe dużej mocy mimo rozwoju energoelektroniki mają ograniczone możliwości zwiększania mocy. Dzieje się tak ze względu na dopuszczalne wartości maksymalne prądów obciążenia przekształtników.

a)

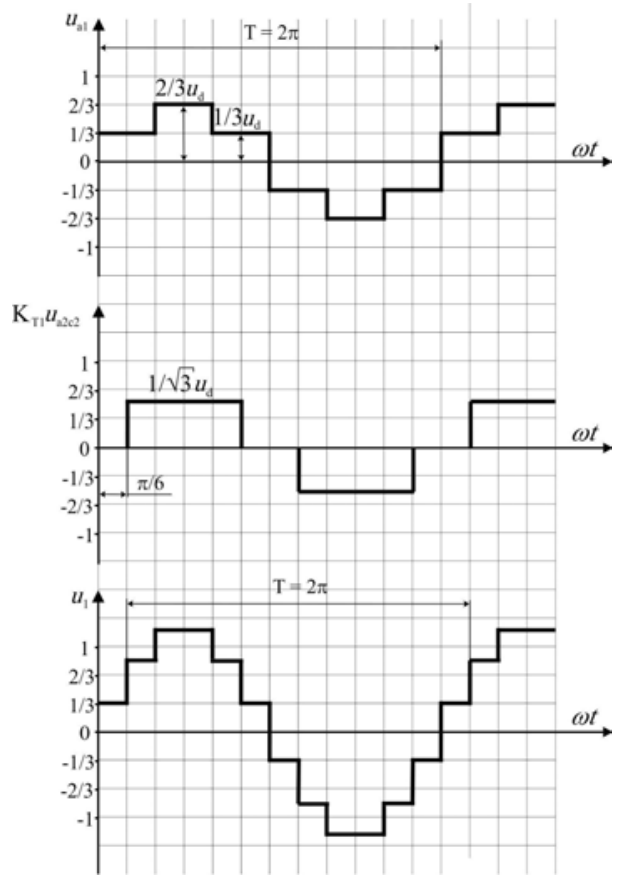


b)

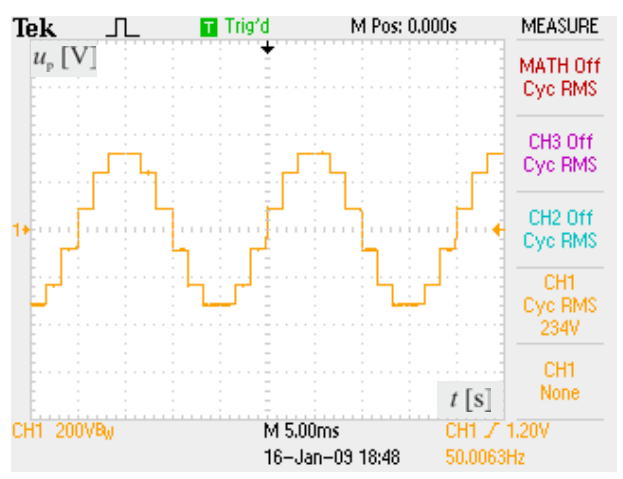

Dlatego zastosowanie silnika dwuuzwojeniowego (stojana) pozwala na obniżenie napięć i prądów fazowych, obniżając wymagania dotyczące falowników. Schemat układu przedstawiono na rysunku 3.

Układ napędowy nie zawiera transformatorów sumujących, jednakże silnik jest skomplikowany ponieważ sumowanie pól elektromagnetycznych odbywa się $\mathrm{w}$ nim. Ma on również podniesioną masę ze względu na podwójne uzwojenia wykonane $\mathrm{z}$ miedzi. Jest to rozwiązanie techniczne, w którym nie ma $\mathrm{w}$ momencie elektro-magnetycznym wpływu 6 . harmonicznej. Tu falowniki generują fale napięcia przesunięte względem siebie o kąt $30^{\circ}$ elektrycznych i zasilają uzwojenia przesunięte także o ten kąt $\mathrm{w}$ przestrzeni. Napięcia fazowe mają przebieg taki jak napięcie $u_{\mathrm{a} 1} \mathrm{z}$ rysunku 2. Układ ten jest nieomal równoważny (skutkiem energetycznym) układowi z rysunku 1. Straty mocy wywołane wyższymi harmonicznymi w układzie $\mathrm{z}$ transformatorem (rys.1) przenoszą się do silnika, a w momencie elektromagnetycznym silnika, nie występuje 6. harmoniczna wskutek złożonego sumowania pól harmonicznej 5. i 7.

Praktycznym sposobem w napędach trakcyjnych, w których występują wózki parami, jest ten jaki przedstawiono na rysunku 4. Falowniki, podobnie jak poprzednio, generują fale napięcia przesunięte względem siebie o $30^{\circ}$ elektrycznych. Wtedy także w momencie nie występuje wpływ 6 . harmonicznej. W tej sytuacji można porównywać schematy napędowe $\mathrm{z}$ rysunków 1, 3 i 4 ze względu na jakość momentu elektromagnetycznego.

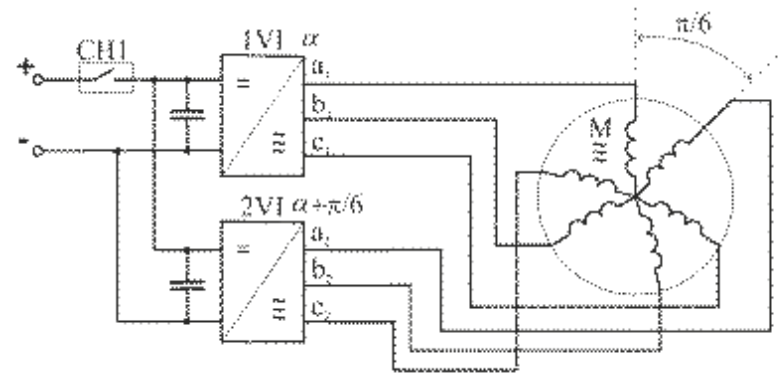

Rys. 3. Schemat zasilania silnika dwuuzwojeniowego.

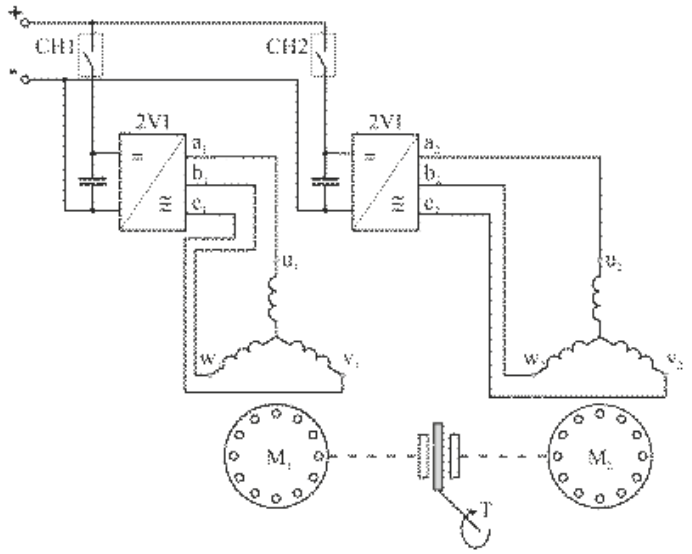

Rys. 4. Układ mechaniczno-elektryczny do napędu trakcyjnego, w którym występują wózki parami.

Dla linii trakcyjnej AC autorzy proponują układ stanowiący ich rozwiązanie własne [9] przedstawione na rysunku 5. W tym przypadku silnik jest klasyczny, prosty. Przebiegi momentu w stanie ustalonym są takie jak silnika z rysunku 1.

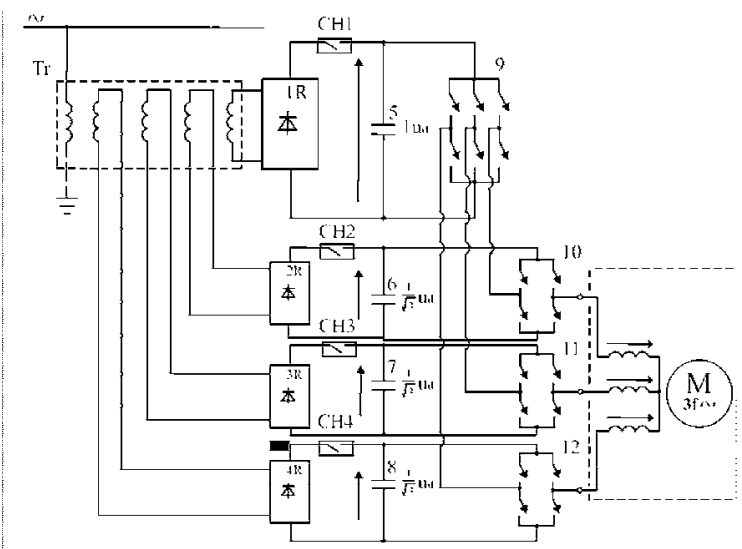

Rys. 5. Sposób zasilania silnika w celu uniknięcia w momencie elektromagnetycznym wpływu 6 harmonicznej

Istota układu przejawia się w tym, że układ ten jest zasilany czterema napięciami stałymi, z których pierwsze ma wartość względną równą 1 i zasila poprzez równoległą baterię kondensatorów falownik trójfazowy, a pozostałe trzy napięcia o wartości względnej równej 1/?3 każde, zasilają poprzez równoległe trzy baterie kondensatorów trzy jednofazowe falowniki napięcia, które z kolei dodają swoje napięcia do napięć fazowych falownika trójfazowego.

Trójfazowy falownik napięcia kształtuje napięcie fazowe, które w przedziale kątów $0 \div \pi$ przebiega następująco: w przedziale $0 \div \pi / 3$ napięcia mają wartość $1 / 3 u_{\mathrm{d}}$, w przedziale $\pi / 3 \div 2 \pi / 3$ napięcia mają wartość $2 / 3 u_{\mathrm{d}}$, w przedziale $2 \pi / 3 \div \pi$ napięcia mają wartość $1 / 3 u_{\mathrm{d}}$. Dla kątów większych od $\pi$ funkcja przebiega antysymetrycznie. 
W przedziale kątów $0 \div \pi$ każdy z jednofazowych falowników napięcia kształtuje napięcia o następującym przebiegu: $\mathrm{w}$ przedziale $0 \div \pi / 6$ napięcia mają wartość $0, \mathrm{w}$ przedziale $\pi / 6 \div 5 \pi / 6$ napięcia mają wartość $1 / ? 3 u_{\mathrm{d}}$, w przedziale $5 \pi / 6 \div \pi$ napięcia mają wartość 0 . Dla kątów większych od $\pi$ funkcje przebiegają antysymetrycznie. Reasumując, można przyjąć, że napięcie na silniku (rys. 5) przebiega jak napięcie $u_{1}$ z rysunku $2 \mathrm{~b}$.

Wyeliminowanie z napięcia harmonicznych 5. i 7. skutkuje wyeliminowaniem z momentu wpływu 6 . harmonicznej. Wada układu z rysunku 1 i rysunku 5, duża masa, w napędzie trakcyjnym nie jest oczywista, ponieważ lokomotywa powinna mieć pewną masę, a tę powiększa transformator.

Niejako upraszczając ten układ dochodzi się do rozwiązania, które przedstawiono na rysunku 6 .

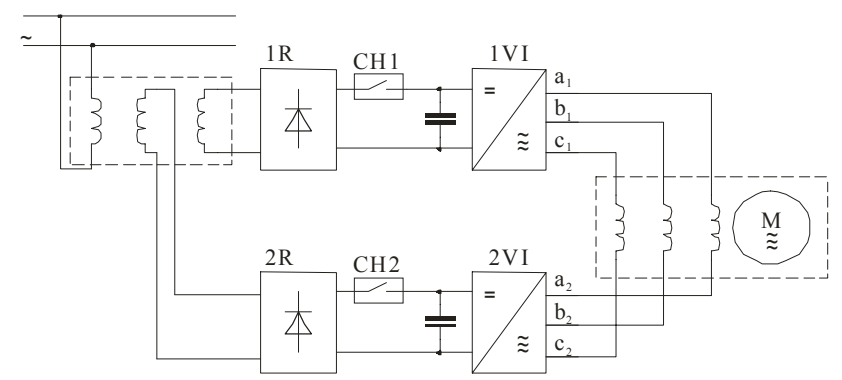

Rys. 6. Inny w stosunku do sposobu z rysunku 5 sposób zasilania silnika w celu ograniczenia w momencie elektromagnetycznym wpływu 6. harmonicznej

W układzie następuje ograniczenie wpływu 6. i 12. harmonicznej. Nie eliminuje się w nim całkowicie tego wpływu. W tym wypadku wynika to z przebiegu napięcia fazowego na silniku.

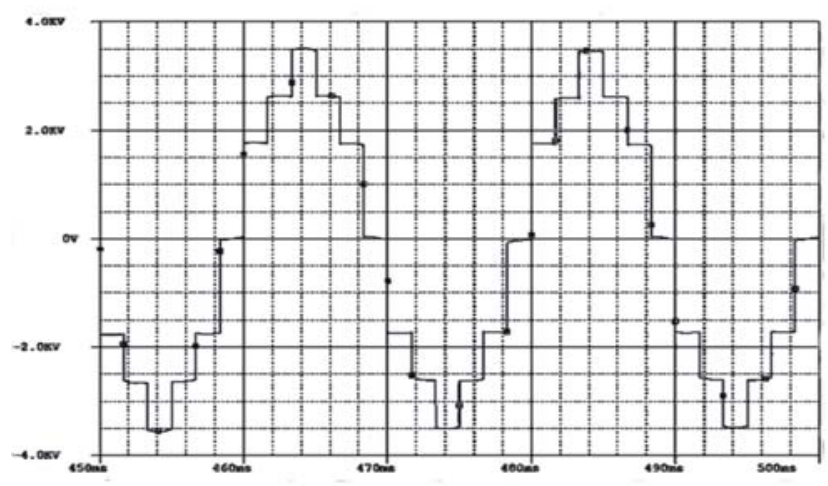

Rys. 7. Przebieg napięcia fazowego na uzwojeniu silnika w przypadku zasilania silnika jak na schemacie z rysunku 6

Przebieg napięcia na silniku z rysunku 8 przedstawiono na rysunku 9. Układem, w którym wyeliminowano $\mathrm{z}$ momentu harmoniczne 6. i 12. jest układ $\mathrm{z}$ rysunku 8 , równoważny pod względem zawartości harmonicznych $\mathrm{w}$ momencie elektromagnetycznym układowi z rysunku 10.

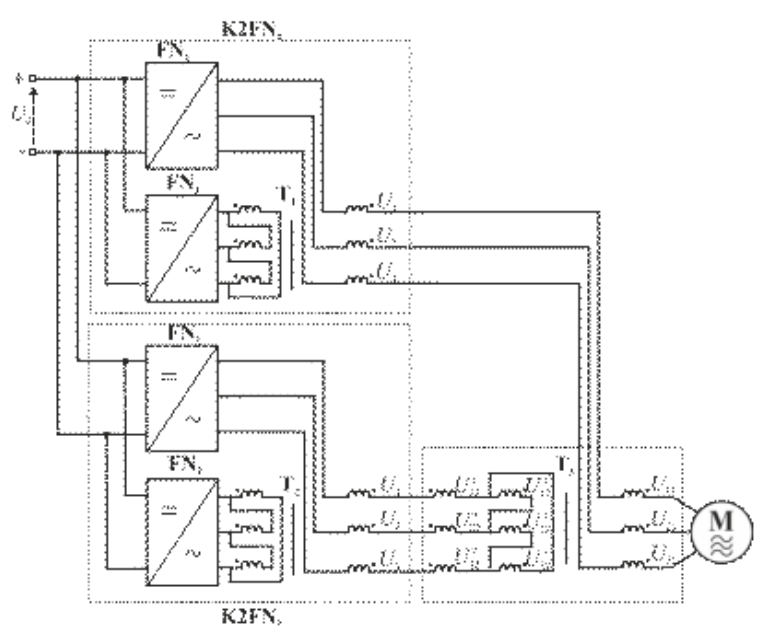

Rys. 8. Schemat układu zasilania silnika, w którym wyeliminowano z napięcia harmoniczne rzędu 5, 7, 11, 13 oraz 17 i 19 a z momentu silnika harmoniczne rzędu 6, 12, 18 [7].

Transformator $\mathrm{T}_{3}$ połączony jest $\mathrm{w}$ tzw. przedłużony trójkąt

Układ (rys. 10) stanowi silnik wielou-zwojeniowy bardziej rozbudowany w stosunku do silnika z rysunku 3.

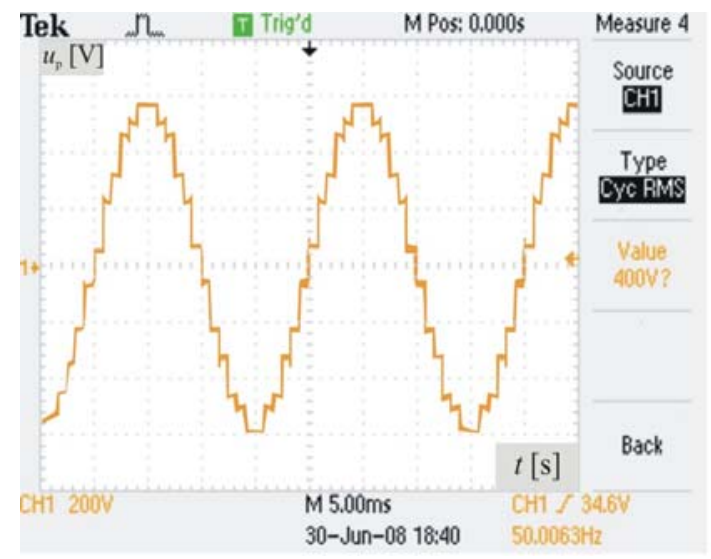

Rys. 9. Przebieg napięcia na silniku z rysunku 8 (z badań eksperymentalnych falownika kaskadowego z rys. 8 [7])

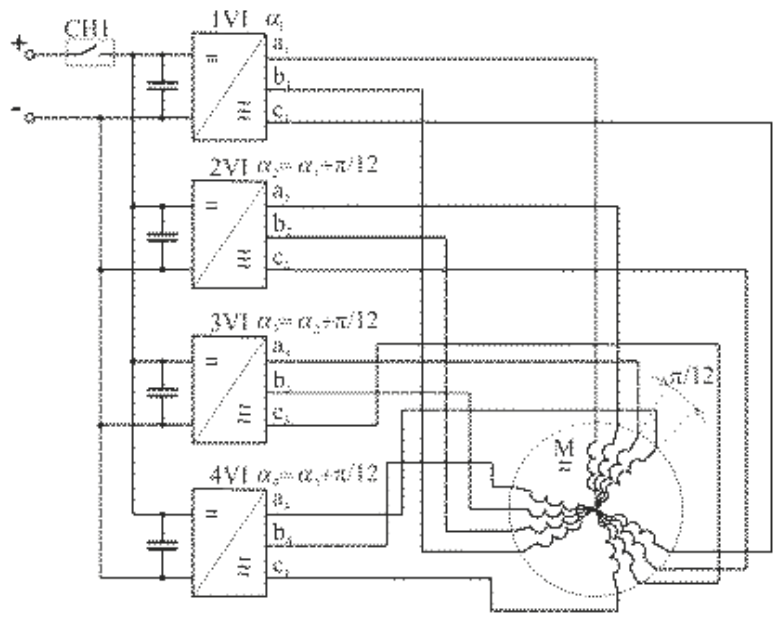

Rys. 10. Schemat silnika wielouzwojeniowego, w którego momencie elektromechanicznym nie wystąpią harmoniczne rzędu 6,12 i 18 
W silniku kolejne uzwojenia zasilane są napięciami fazowymi przesuniętymi $\mathrm{w}$ czasie i przestrzeni, jak to wyjaśniono na rysunku 10 . Wprawdzie układ nie zawiera transformatorów, to jednak jest on skomplikowany ze względu na złożoną budowę silnika, w którym odbywa się sumowanie pól od poszczególnych faz.

\section{Wnioski}

Ponieważ każdy element elektroniczny obniża MTBF, więc powinno być ich $\mathrm{w}$ układzie możliwie najmniej. Wyeliminowanie transformatorów z układu skutkuje stratami w skomplikowanym silniku. W zaprezentowanych układach występuje zminimalizowana liczba łączników półprzewodnikowych w obwodach mocy, a eliminacja $z$ góry określonych harmonicznych $z$ momentu elektroma-gnetycznego czyni je konkurencyjnymi w stosunku do układów z PWM. Zapewniają one dobra jakość momentu elektromagnetycznego i są wykonalne.

\section{Literatura}

[1] Lipiński L., Miszewski M., Żarnowski R., Nowoczesne asynchroniczne napędy przeksztaltnikowe dla pasażerskich pojazdów trakcyjnych na napięcie $3 \mathrm{kV}$ prądu statego. WE, 2007, nr 6

[2] Mohan N., Unlead T.M., Robbins W.P., Power electronics. Converters, Applications and Design. J. Wiley \& Sons, 2003

[3] Płachtyna O., Żarnowski R., Wielopoziomowy falownik w zastosowaniu do silnika indukcyjnego lub autonomicznej pradnicy indukcyjnej albo synchronicznej. PEMiNE Rytro, 2010

[4] Plakhtyna O., Gientkowski Z., Żarnowski R., AC Converter Drive System with Cascaded Inverter Compatible with Motor and Utility Grid. 5th International Conference-Workshop-CPE Gdynia, 2007

[5] Skvarenina T. L., The Power Electronics Handbook. Industrial Electronics Series CRC Press. Washington, 2000

[6] Steimel A., Electric traction - Motive Power and Energy Supply. Oldenburg Industrieverlag $\mathrm{GmbH}, 2008$

[7] Żarnowski R., Analiza i badania uktadu autonomicznej pradnicy indukcyjnej z kaskadowym falownikiem napięcia. Rozprawa doktorska, Akademia Morska Gdynia, 2010

[8] Niekorzystny wptyw przeksztaltników na izolację silników. Wiadomości Elektrotechniczne 2003, Nr 1-2 na podstawie art. IEEE Power Engineering Review, $2002 \mathrm{nr} 1$

[9] Płachtyna O., Żarnowski R.: Zgłoszenie patentowe do UPRP $\mathrm{Nr}$ P.380141/07, Uktad trójfazowego kaskadowego falownika napięcia 